\title{
Partial Discharge in High Voltage Insulating Materials
}

\author{
Suwarno \\ School of Electrical Engineering and Informatics \\ Institut Teknologi Bandung \\ Bandung Indonesia \\ suwarno@ieee.org
}

\begin{abstract}
High voltage transmission has been chosen in electric power system due to its capability to transfer a large amount of electric power. Several key equipments such as generator, transformer, GIS, cable and insulator play important role in determining the reliability of the power system. The high voltage equipments in general contain gas, liquid or solid insulation. Defects and a particular condition may lead to extremely high electric field. Particularly at interfaces between gas and solid and liquid insulations, the excessive electric field may cause the breakdown of the gas while the liquid and solid insulations are still able to withstand the electric field. This phenomena is referred as partial discharge (PD). Partial discharges in high voltage equipments for long time may degrade the quality of the insulation and at the same time the appearance of discharges can be used as diagnostic signal for assessing the condition of the insulation inside the high voltage equipments. Partial discharge is an important subject investigated by many researchers and discussion in many international conferences as well as international journals or transactions. This paper discusses the measurement and experimental results and analysis on time-resolved partial discharges in gas, liquid and solid insulation. The partial discharges are presented in various distribution such as $\phi-\mathrm{q}-\mathrm{n}, \phi-\mathrm{n}$ and three dimensional distribution. Here $\phi$ is phase angle, $\mathrm{q}$ is the discharge magnitude and $\mathrm{n}$ is the discharge number. Based on the partial discharge data, diagnosis methods of high voltage equipments as also presented.
\end{abstract}

Keywords: partial discharge; high voltage; insulation; model; simulation; diagnosis

\section{Introduction}

High voltage insulation is the most important part of a high voltage equipment used in an electric power system. The main task of the insulation is to withstand a high electric field between phases or phase and neutral. In excessive high electric field due to the appearance of field enhancement sites like void or protrusion, partial discharge (PD) may occur. The appearance of partial discharges may indicate insulation aging and in long term this may further reduce the integrity of the insulation leading to the failure of the equipments. The failure of high voltage equipment may significantly contribute to the system failure. Table 1 shows the typical contribution of equipment failure to the system failure due to insulation problems $[1,2]$.

In the past time Time Based or Breakdown Maintenance were commonly implemented in power utilities, however, thank to the advancement of diagnostic technology, recently, Condition Based Maintenance (CBM) of high voltage equipments is widely adopted[3-5]. The CBM program is conducted based on the assessment of the equipment conditions. Diagnosis of high voltage equipments is the key for effective CBM implementation. Many researchers and utilities developed diagnosis methods to assess the equipment conditions. Partial discharge measurement is an important method to diagnose high voltage equipments[6-11]. This paper reports the fundamental of partial discharge, the experimental result of PD measurements and time-resolved partial discharge analysis in gas, liquid and solid insulation.

For more effective diagnosis and deeper understanding of PD phenomenon, simulation of PD using an equivalent model was introduced[12-15]

Received: October $24^{\text {th }}, 2015$. Accepted: January $23^{\text {rd }}, 2016$ DOI: 10.15676/ijeei.2016.8.1.11 
Table 1. Contribution to system failure and failure due to insulation problems for main HV equipments [1,2]

\begin{tabular}{|l|c|c|}
\hline \multicolumn{1}{|c|}{ Equipments } & $\begin{array}{c}\text { Contribution to } \\
\text { system failure (\%) }\end{array}$ & $\begin{array}{c}\text { Failure due to } \\
\text { Insulation } \\
\text { Problem (\%) }\end{array}$ \\
\hline Insulators & 35 & 90 \\
\hline Generators & 15 & 47 \\
\hline Transformers & 12 & 84 \\
\hline GIS \& switchgear & 15 & 95 \\
\hline Power Cables & 10 & 89 \\
\hline
\end{tabular}

\section{Partial Discharge Fundamental}

A. Partial discharge occurrance

In general, a high voltage equipment contains insulation (gas, liquid or solid) and high voltage part. Electric field enhancement sites such as protrusion or void may exist in the insulation during fabrication, installation or operation of the equipments. Gas-filled void in solid insulation as shown in figure 1 has a lower permittivity than solid insulation. Due to the difference of the permittivity then, the electric field strength in void will be higher than those in the solid insulation. On the other hand the gas-filled void has much lower breakdown strength (around $30 \mathrm{kV} / \mathrm{cm}$ ) than the insulation material $(\mathrm{MV} / \mathrm{cm})$. Therefore, it is very probable that the gas inside void breakdown before the insulation. Partial discharge (PDs) occurs when the electric field across the void exceeds the breakdown strength of gases in the void which is typically around $30 \mathrm{kV} / \mathrm{cm}$.

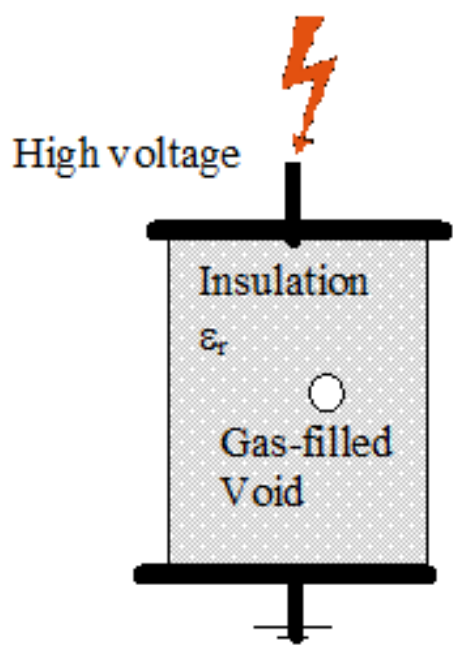

Figure 1. A Void in Solid Insulation

The PD is initiated by an initial electron available in the PD sites like void. The electron may be generated from the cathode due to radiation (photoelectric effect), high voltage assisted emission or other emission process. Due to high electric field, the existing electron travel from cathode to anode in accelerated manner. The electron may collide with gas atom. If the kinetic energy of the electron is large enough (hot electron) then the collision will release another electron and positive ion. A large amount of electrons traveling from cathode to anode while ions from anode to cathode in the form of electron or ion avalanches. Both electrons and ions flows contribute to the discharge current. 
Since the mass of electron is much smaller than ion, the speed of ion is much lower than electron. The fact leads to the impulse PD current where electron mainly contributes to the front while ions to the tail of the PD current as illustrated in figure 2(b).

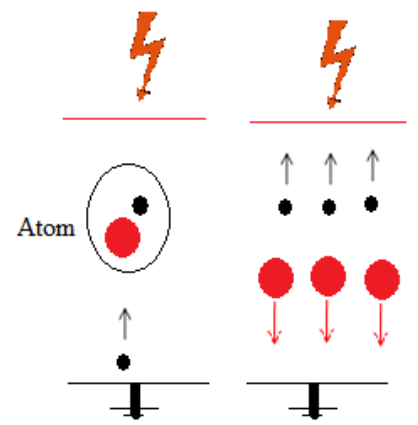

(a)

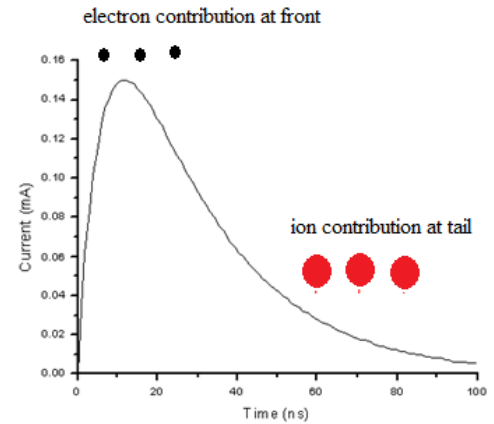

3.

(b)

Figure 2. (a) Electron Generation and Flow (b). Typical PD Current Waveform

The typical magnitude of current is several $\mu \mathrm{A}$ to $\mathrm{mA}$ while time in ns. An example of PD current waveform generated in a needle plane electrode system in air is shown in figure 1.

Electron contribution at rise time

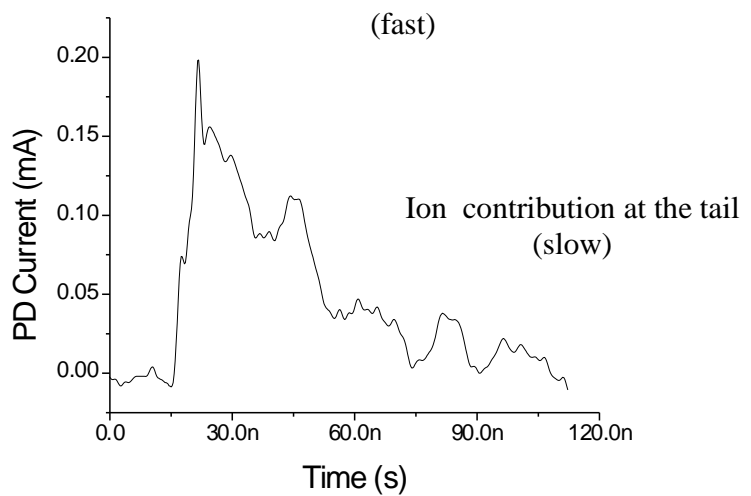

Figure 3. Typical Discharge Current Pulse Wave Shape

(Needle-Lane Electrode, 4mm Separation)

As clearly shown in the figure, the PD current waveforms increased steeply at the front within very short period of several ns and then decay at the tail in a period of about $100 \mathrm{~ns}$. The 
sharp rise of the current was due electron flow traveled at high speed while the tail was mainly due to the contribution of ions which travelled with much lower velocity. From the physical phenomenon of the charges flow then the PD current waveforms can be expressed by using a double exponential equation

$$
I_{o}\left(e^{-\alpha t}-e^{-\beta t}\right)
$$

The first term is due to ion flow while the second term is due to the electron. $\alpha$ is the attenuation constant of ion current while $\beta$ is the attenuation constant of electron current. The PD waveform similar to that shown in figure 3 can be simulated using $\alpha$ and $\beta$ as $0.15 / \mathrm{ns}$ and $0.0416 / \mathrm{ns}$ respectively[16].

\section{B. Partial Discharge Sources and Detection}

PD may occur at electric field enhancement sites such as void or protrusion. The PD sites can be classified into 3 types namely internal PD, surface PD and corona PD.

Internal discharges may appear in voids contained inside insulation. The shape, size and position of the voids in the insulation strongly affect the magnitude and number of partial discharges. Surface discharges occur at the surface of insulation with relatively short leakage distance between electrodes under high electric field. The last discharge source is corona where discharge takes place at the tip of conductor (typically protrusion on the conductor surface). Since each discharge occurs with particular processes, the PD pattern of each source may show specific properties such as their magnitude, phase of PD occurrence and PD number in certain time range.

In the laboratory, the most common electrode arrangement for investigating partial discharges is plane - needle system which is able to produce very high divergent filed around the needle tip. The needle is located in insulation where PD behavior is under investigation such as air, gas, liquid insulation as well as solid like polymeric insulation. The typical curvature of the needle tip is $30^{\circ}$ and the tip radius is $3-100 \mu \mathrm{m}$. A photograph of a needleplane electrode system with gap of $4 \mathrm{~mm}$ is shown in figure. With this geometry, sufficiently high electric field can be easily obtained to generate discharges at the needle tip.

The electric field at the tip of the needle electrode is estimated by using the following equation[17].

$$
E_{m}=\frac{2 V}{r \ln \left(\frac{4 d}{r}\right)}
$$

The impulse current as shown in fig can be integrated to obtain the charge associated with the discharge. During PD process UV light is radiated. The intensity of the UV radiation strongly correlates with the PD magnitude and number. PD pulses is a kind of impulse phenomena. It acts as a knock to the material around the PD site resulting in a propagating acoustic wave. This acoustic wave can be detected in equipments with tank structure such as gas insulated sub station (GIS) or transformers. PD also associates with electromagnetic wave. This wave propagates from the PD site outward the insulation system and therefore it can be detected using antenna with particular frequency range such as ultra high frequency (UHF) antenna which commonly used for PD measurement in GIS[18-21]. PD occurrence also produced heat. The heat may heat up the surrounding insulation and causes an increase of temperature. 


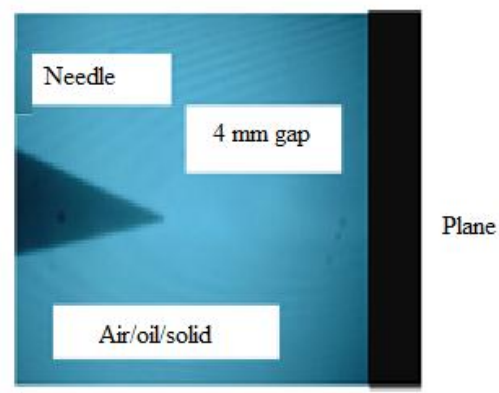

(a)

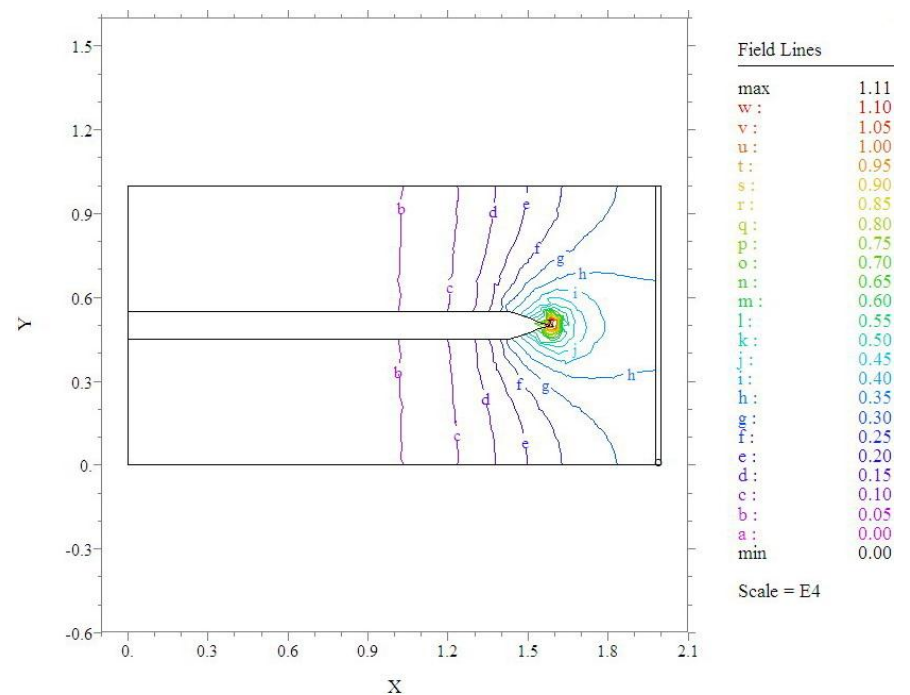

(b)

Figure 4. (a) Needle-plane electrode system (b). high electric field around needle tip

The energy released by PD may degrade insulation and it can be used as diagnostic signals. Dependent on the dominant signal in high voltage equipment, most suitable sensor can be determined. Several sensors used in high voltage equipments can be summarized as follows: Table 2 PD signal, sensor type and application

\begin{tabular}{|c|c|c|}
\hline Sensor & Detected signal & Equipment \\
\hline HF CT & $\begin{array}{l}\text { Impulse } \\
\text { Current }\end{array}$ & Cable, transformer \\
\hline $\begin{array}{l}\text { UHF Electrode, } \\
\text { Antenna }\end{array}$ & EM wave & $\begin{array}{l}\text { GIS, Switchgear, } \\
\text { OH Lines }\end{array}$ \\
\hline $\begin{array}{l}\text { Coupling } \\
\text { Capacitor, RC } \\
\text { detector }\end{array}$ & $\begin{array}{l}\text { Voltage from } \\
\text { impulse current }\end{array}$ & $\begin{array}{c}\text { Rotating Machines, } \\
\text { Cables }\end{array}$ \\
\hline $\begin{array}{l}\text { Ultrasonic } \\
\text { sensor (AE) }\end{array}$ & $\begin{array}{c}\text { Sound/ } \\
\text { Vibration }\end{array}$ & Transformer, GIS \\
\hline $\begin{array}{l}\text { UV camera, } \\
\text { Pockels sensor }\end{array}$ & UV Light & $\begin{array}{l}\text { GIS, insulators, } \\
\text { transformer }\end{array}$ \\
\hline IR Camera & Heat (IR light) & $\begin{array}{l}\text { Insulator, rotating } \\
\text { machine, conductor }\end{array}$ \\
\hline
\end{tabular}


PD impulse current with high frequency can be detected using RC detector or high frequency current transformer. RC detector integrates the impulse PD current into voltage. Discharges occurred in the sample were detected with using PD detector consisting of a capacitance $C_{d}$ and resistor $R_{d}$ as shown in figure 5 .

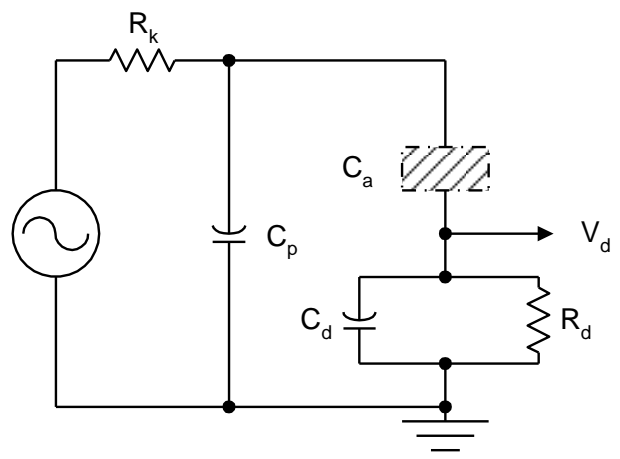

Figure 5. RC detector for PD measurement

The detector acts as an integrator and thus the PD pulse signal is integrated by the detector to obtain $\mathrm{V}_{\mathrm{d}}$. By using the measuring system discharge parameters such as magnitude, frequency and the phase of discharge occurrence in the applied voltage cycles can be determined.

Instrument used for measuring PD can be characterized by a transfer function $\mathrm{Z}(\mathrm{f})$ with lower and upper limit frequencies $f_{1}$ and $f_{2}$. For wide band instruments, IEC 60270 recommends values, $30 \mathrm{kHz}<\mathrm{f}_{1}<100 \mathrm{kHz}, \mathrm{f}_{2}<500 \mathrm{kHz}$ and $100 \mathrm{kHz}<\mathrm{f}_{2}-\mathrm{f}_{1}<400 \mathrm{kHz}$. For narrow band instruments the recommended values for bandwidth $\mathrm{f} 2$-f 1 and mid band frequency fm are $9 \mathrm{kHz}<\mathrm{f}_{2}-\mathrm{f}_{1}<30 \mathrm{kHz}$ and $50 \mathrm{kHz}<\mathrm{f}_{\mathrm{m}}<1 \mathrm{MHz}$

The output voltage is integration of PD pulse (i.e. the PD charge) and can be expressed by

$$
V_{d}(t)=\frac{1}{C_{d}} \int_{0}^{t} i(t) d t
$$

The value of output voltage $V_{d}$ can be expressed by :

$$
V_{d}(t)=K \exp (-\alpha t)
$$

Where

$$
K=\frac{q}{C_{d}+\frac{C_{p} C_{a}}{C_{p}+C_{a}}} x \frac{C_{p}}{C_{p}+C_{a}}
$$

In this case $C_{p}<<C_{a}$ and $C_{d} \gg>C_{a}$, therefore : equation can be simplified as:

$$
V_{d}(t)=\frac{q}{C_{d}} \exp \left(-\frac{t}{R_{d} C_{d}}\right)
$$

or :

$\mathrm{q} \approx \mathrm{V}_{\mathrm{d}} \cdot \mathrm{C}_{\mathrm{d}}$

\section{Partial Discharge Time Resolved Analysis}

A. Time Resolved PD Analysis

Recent computer technology has increased the ability of measurement system in various fields including in PD measurement. Computer-aided PD measurement systems enable to measure and analyze of a tremendous amount of PD data in time series[22-23]. Every PD 
event can be measured and the obtained data can be retrieved. The PD parameters measured were PD magnitude and its phase angle. Every PD pulse is represented by the charge (q) of the PD and the phase $(\phi)$ of the applied voltage where the PD takes place.

In actual measurement, a large amount of PD pulses take place in a number of cycles can be obtained in once measurement. The PD pulse in a number of successive cycles can be represented in the form of PD pulse sequences as shown in figure 6 .

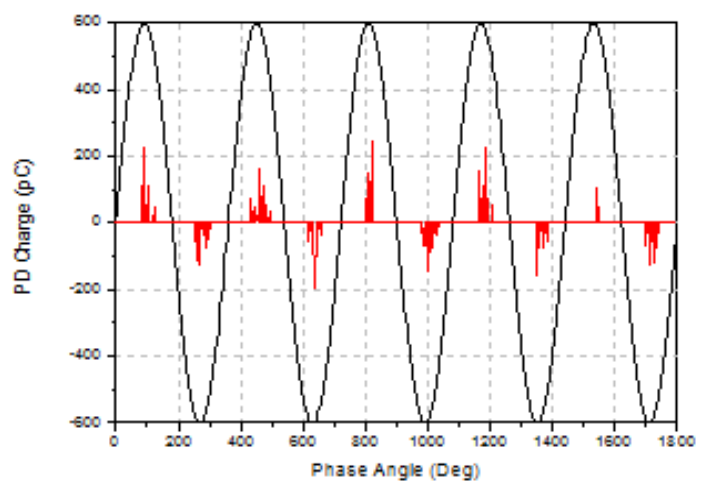

Figure 6. Typical PD pulse sequences

PD may also be characterized by phase-charge-number ( $\phi$-q-n pattern) as shown in figure (a). The three dimensional characteristics of the PD can be more understood by representing the PD pulse in three dimensional figure as shown in (b).

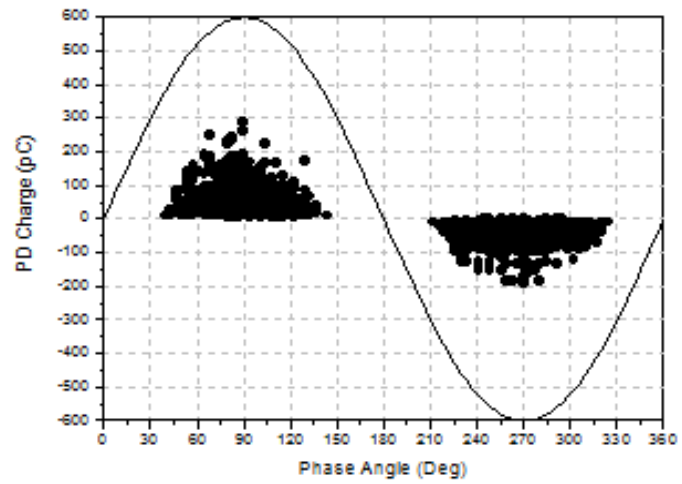

(a)

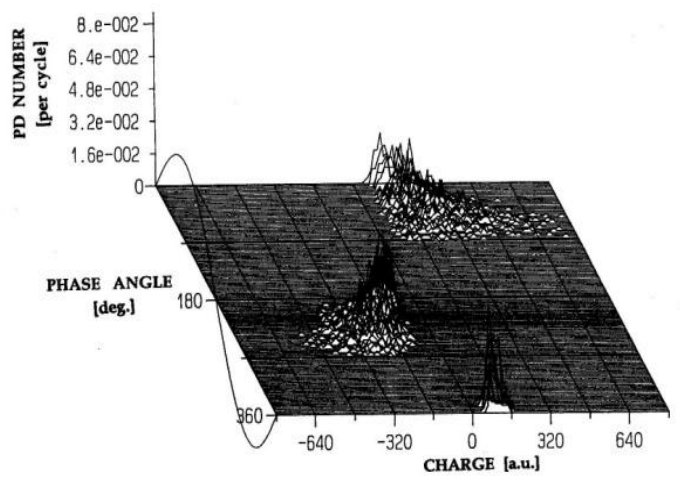

(b)

Figure 7. (a) $\phi-\theta$-n pattern and (b). 3 dimensional representation of PD 
A $\phi$-q-n pattern can be simplified into a $\phi$-n pattern by taking the average PD number in a given phase angle for $\mathrm{c}$ successive cycles. The average PD number in a phase window I can be expressed as

$$
n\left(\phi_{i}\right)=\frac{\sum_{j=1}^{j=c} n_{j}\left(\phi_{i}\right)}{c}
$$

Here $\mathrm{c}$ is the number of successive cycles where PD pulses were measured.

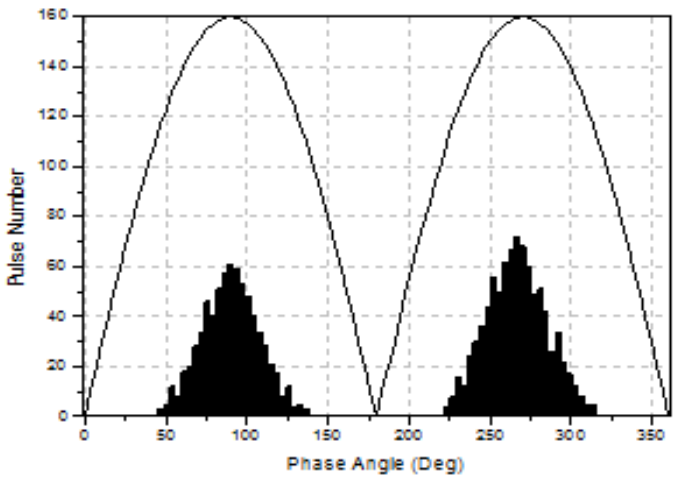

Figure 8. $\phi$-n pattern of PD

PD pattern can also be expressed in the form of $\mathrm{f}-\mathrm{q}$ pattern by averaging the PD magnitude of all cycles at each phase angle window. Average PD magnitude in a phase window i can be obtained by

$$
q\left(\phi_{i}\right)=\frac{\sum_{j=1}^{j=c} q_{j}\left(\phi_{i}\right)}{c}
$$

Where $\mathrm{q}_{\mathrm{j}}\left(\phi_{\mathrm{i}}\right)$ is the PD magnitude of a PD pulse takes place in phase window I in a cycle number $\mathrm{j}$.

\section{B. Partial Discharge Inception}

Partial discharge inception can be defined as the phenomena relates with initial PD occurrence. The voltage applied when initial PD takes place is called as PD inception voltage. Generally, PD inception takes place in either negative or positive half cycle dependent on the material and electrode system. Figure 9 shows $\phi-q-n$ pattern during PD inception obtained from 200 consecutive cycles (a) and PD pulses in 5 consecutive cycles (b) in transformer mineral oil under needle-plane electrode system as shown in figure 4 at applied voltage of $10.34 \mathrm{kV}$. The figures clearly show that at low applied voltage in excess of inception voltage PD took place at several negative half cycles. No PD pulse was observed at positive half cycles. This result indicated that negative PD pulses may occur more easily than positive PD.

Figure 10. shows $\phi-q-n$ patterns obtained from 200 consecutive cycles and PD pulses in 5 consecutive cycles for virgin sample at applied voltage of $10.48 \mathrm{kV}$ (a) The $\square$-q-n pattern shows that positive PD started to occur and negative PD with higher magnitude happened at slightly higher repetition rate. The pulse sequence shows that there are a positive and negative PD pulses at positive and negative half cycles. This result indicated that negative PD pulses may occur more easily than positive PD. The results clearly showed that the inception voltage of positive $\mathrm{PD}$ is higher than negative $\mathrm{PD}$. 


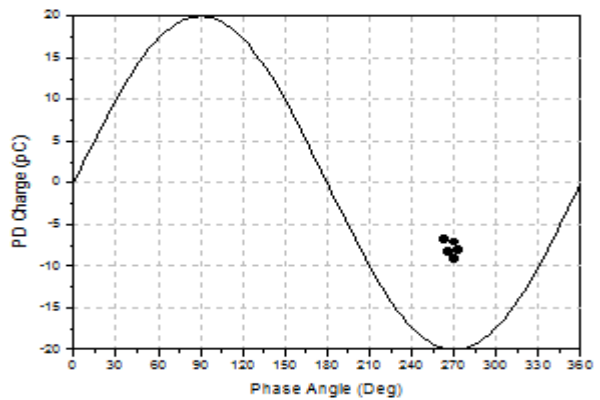

(a)

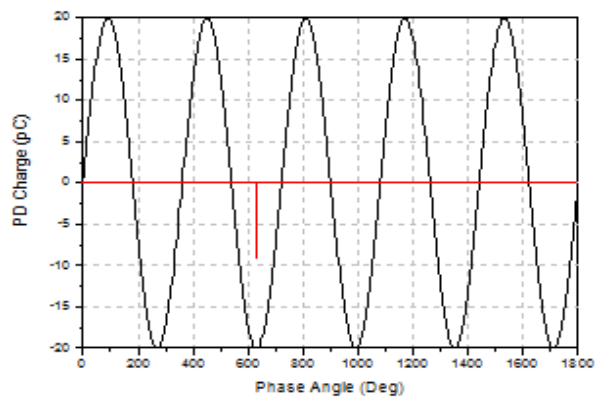

(b)

Figure 9. (a) $\phi$-q-n pattern during PD inception and (b) PD pulses in 5 consecutive cycles in transformer mineral oil at applied voltage of $10.34 \mathrm{kV}$

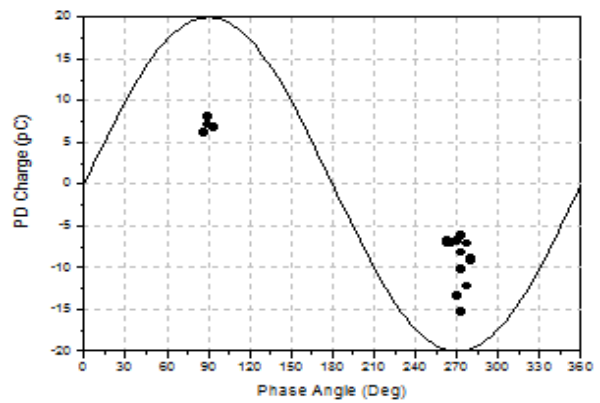

(a)

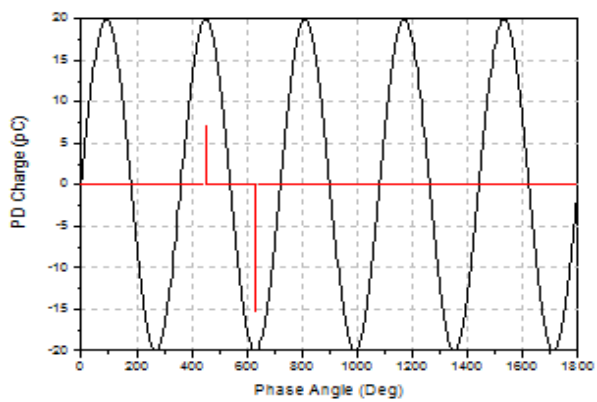

(b)

Figure 10. (a) $\phi$-q-n pattern during PD inception and (b) PD pulses in 5 consecutive cycles in transformer mineral oil at applied voltage of $10.48 \mathrm{kV}$ 


\section{Partial Discharge Patterns}
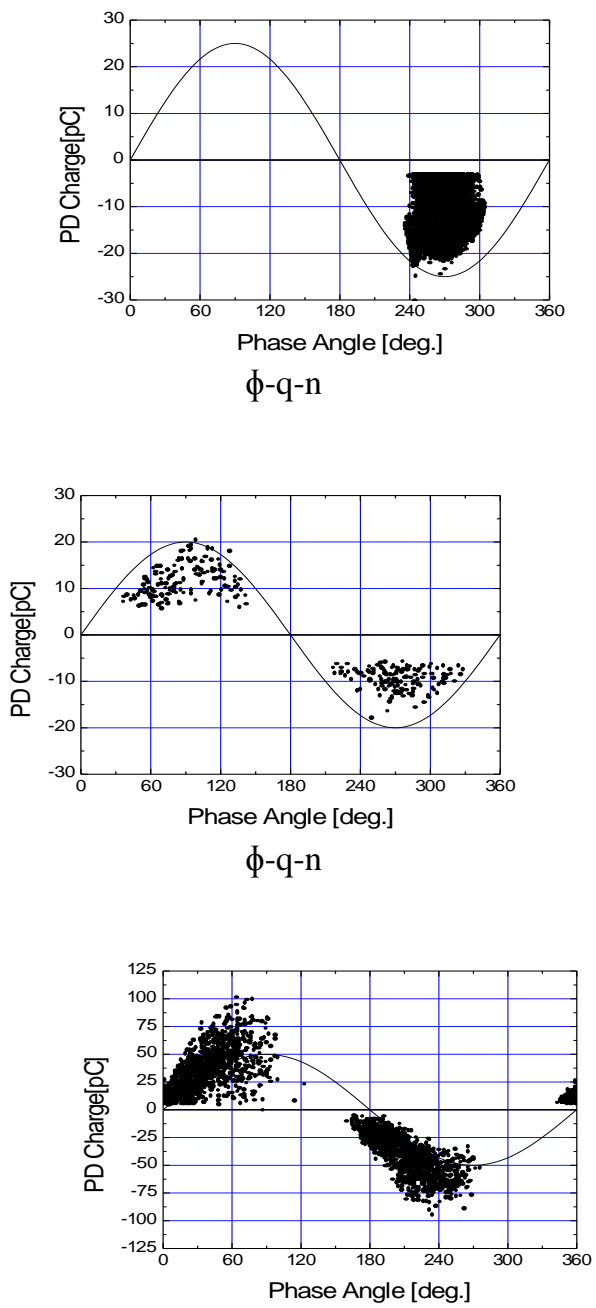

$\phi$-q-n

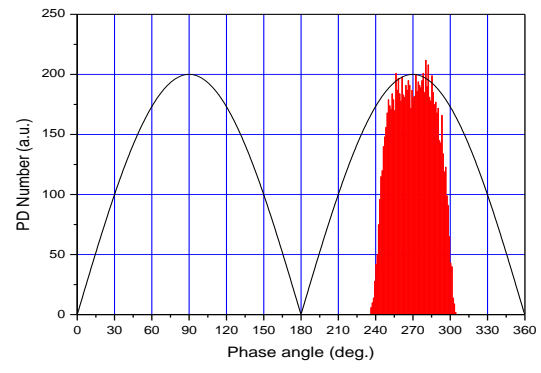

$\phi-n$

(a)

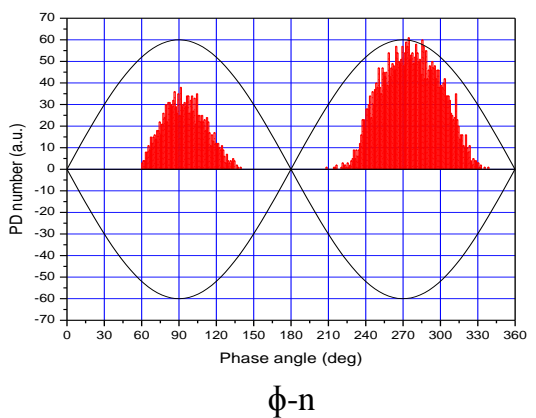

(b)

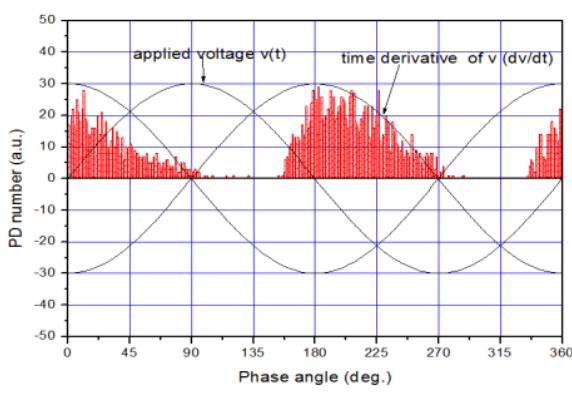

$\phi-n$

(c)

Figure 11. Typical $\phi$-q-n and $\phi$-n patterns of corona (a) void discharge (b) and electrical treeing discharge (c) under sinusoidal applied voltage

Figure 11 shows typical $\phi-\mathrm{q}-\mathrm{n}$ and $\phi-\mathrm{n}$ patterns of corona (a) void discharge (b) and electrical treeing discharge (c) under sinusoidal applied voltage. As shown in figure 11 (a) for corona PD, discharge pulses occurred at negative half cycles and concentrated around the peak of the negative half cycle of the applied voltage. No phase shift was observed which indicated that there was no evident role of space charge in the discharge process.

Figure (b) shows PD patterns in liquid. It is seen that both positive and negative discharges took place around the peak of applied voltage. The figure also indicates that the magnitude of positive discharge was higher than negative discharge. These results indicated that positive discharges took place at higher over voltage than negative one. This asymmetrical behavior reflects the asymmetrical role of electrode system in producing discharge in silicone oil. The magnitude of discharge in both half cycles was proportional to the applied voltage. 
Figure (c) shows PD patterns due to treeing in solid. From the figure it is clearly seen that discharge occurrence (repetition rate) was higher at around zero cross of applied voltage (high the $\mathrm{dv} / \mathrm{dt}$ ) than that around peak (small dv/dt) of the applied voltage. These suggested the important role of the time derivative of applied voltage (dv/dt) on the occurrence of treeing discharges[24-25]. The figure also indicates a trend that PD magnitude increases with the applied voltage.

The above experimental results clearly showed that PD patterns are dependent on their sources. Each PD source has its own PD finger print which is very useful for PD diagnosis system.

D. Multi Sources Partial Discharge and PD Superposition

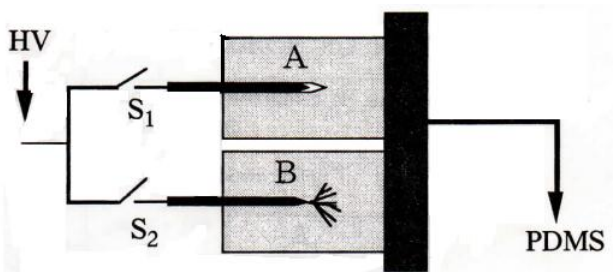

(a)
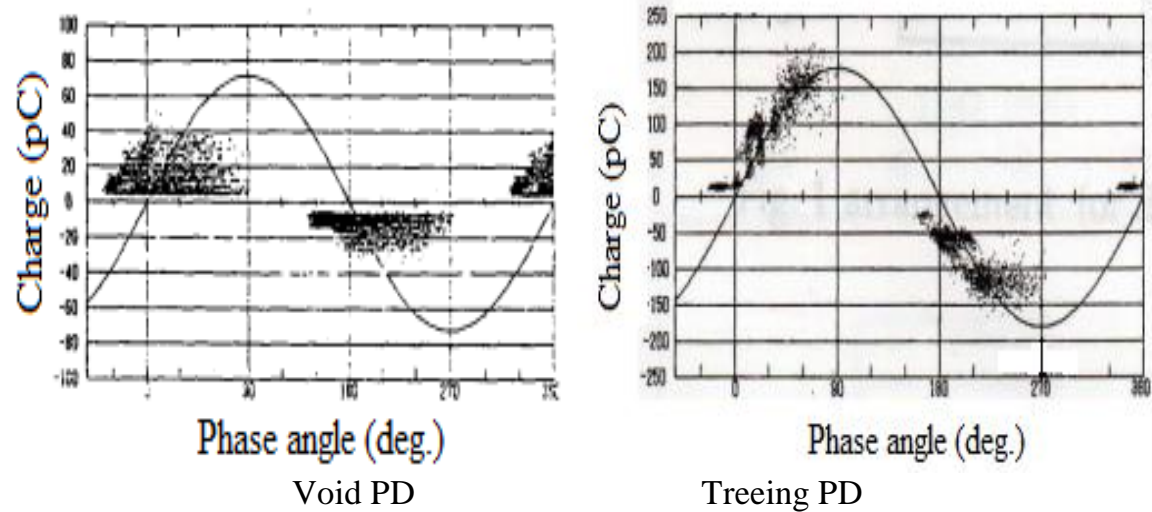

(b)

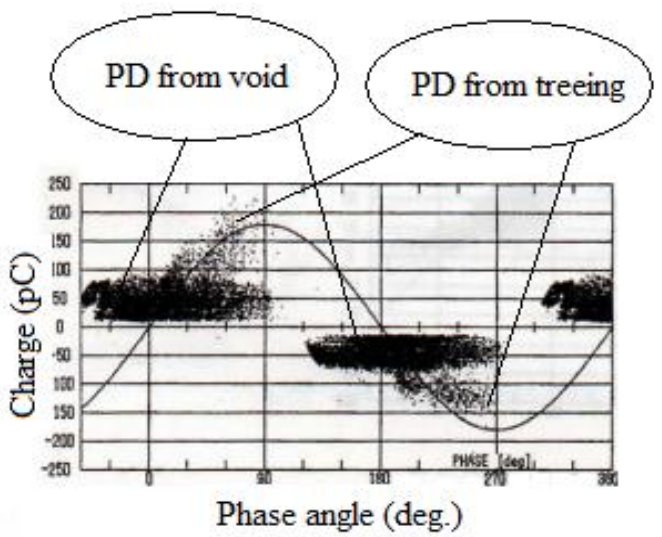

(c)

Figure 12. (a) void and tree samples (b) individual PD patterns (c) superposition PD pattern 
PD pulses may take place in single or multiple sources. Time resolved PD patterns showed that each PD source has its PD pattern. In actual high voltage equipment, it is common that PD occur at more than one PD sites with different type. In order to clarify the PD superposition, an experiment with void and electrical treeing was conducted. The sample is shown in figure 12 (a). Switch S1 and S2 can be used to select the PD source A (void) or B(treeing) to produce PD under AC HV and measured by PD measuring system PDMS. To obtain superposition of PD from void and treeing all switches were closed. For single sample, the measured individual PD patterns are shown in figure 12 (b) while superposition of void and treeing PD is shown in figure 12 (c). It is very clear that superposition PD in figure 12 (c) is can be obtained from PD patterns in 12 (b).

E. Role of time derivative of applied voltage on PD
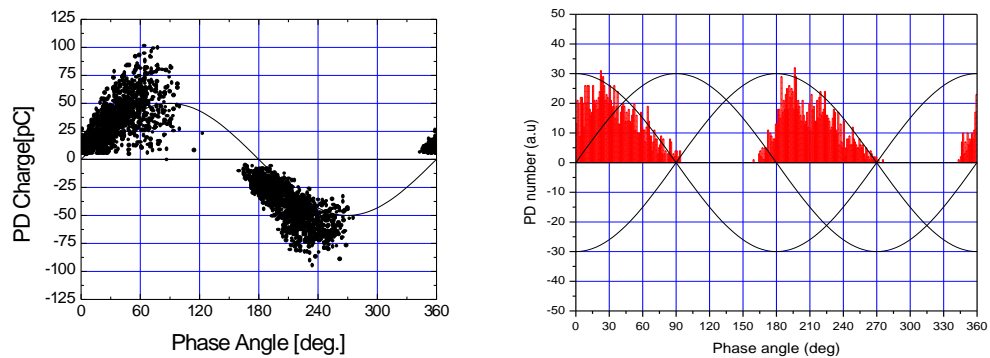

(a)
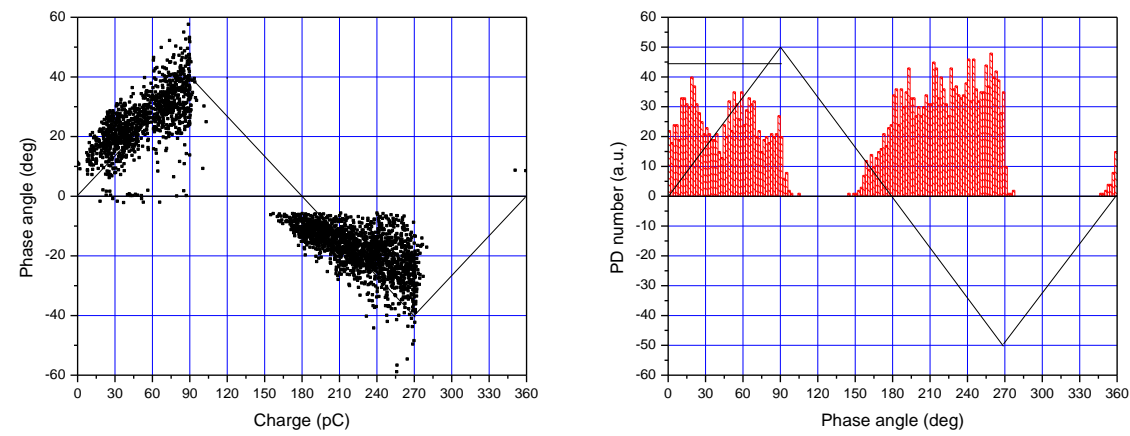

(b)
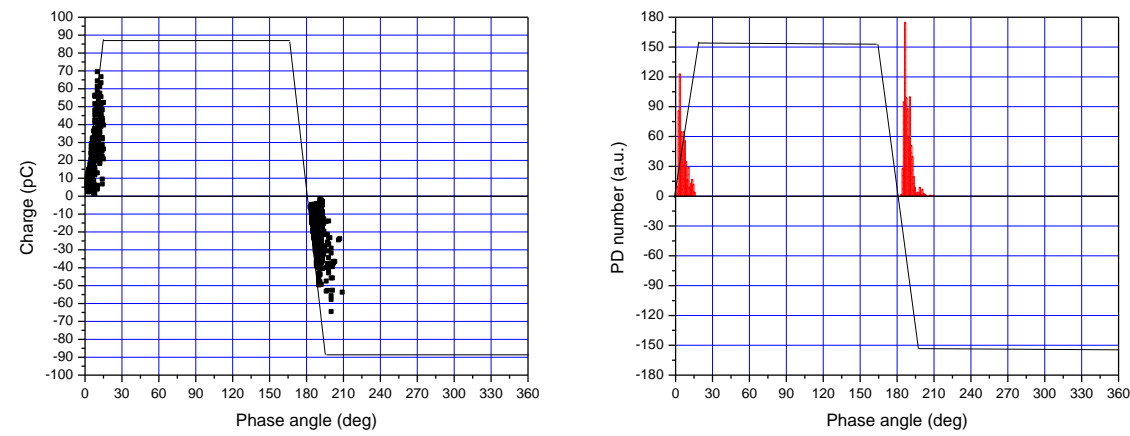

(c)

Figure 13. Typical $\phi-\mathrm{q}-\mathrm{n}$ and $\phi$-n patterns in solid material under (a) sinusoidal (b) triangular and (c) rectangular voltages 
In general, PD is defined in AC voltage system. However, recently, PD in DC system was also introduced [26-29]. Time derivative of the applied voltage plays important role in PD occurrence. As an example, measured PD in solid insulation under different waveforms of different time derivatives are shown in figure 13. Figure 13(a) shows the $\phi$-q-n and $\phi$-n patterns of electrical treeing under sinusoidal voltage, while figure 13(b) shows the $\phi-q-n$ and $\phi-n$ patterns of electrical treeing under triangular voltage and 13(b) shows $\phi-q-n$ and $\phi-n$ patterns of electrical treeing under rectangular voltage. The figures clearly indicate that PD occurrence are strongly dependent on the time derivative of the applied voltage (dv/dt). This facts reveal that time derivative of applied voltage plays important role in generating PD. The PD pattern under rectangular voltage in figure 13 (c) very clearly shows that PD pulses only appear at phase angle with high dv/dt around the zero cross. This also implies that under DC system PD can be observed when there is a certain level of $\mathrm{dv} / \mathrm{dt}$.

\section{F. Partial discharge equivalent circuit and simulation}

The phase-resolved measurement results and analysis on PD in oil it is clear that the PD magnitude as well as the PD occurrence is dependent on the instantaneous applied voltage. The positive PD probability is slightly smaller than negative PD. Under AC voltages, the unsymmetrical behavior of PD in positive and negative half cycles we observed. Negative PD pulses were observed first, and big positive PD pulses were observed at higher applied voltage. The magnitude as well as discharge occurrences are greatly dependent on the instantaneous applied voltage. The discharge behavior in oil can be explained by an equivalent circuit consisting of a streamer capacitance in parallel with a spark gap and in series with the oil capacitance. Based on the characteristics, equivalent circuit for PD in oil is proposed as shown in figure 14. Whitehead has proposed a model of partial discharge in void[12]. This model has been used extensively to explain the PD phenomena, however, this model could not be used to explain several PD phenomena such as corona, discharge in GIS and treeing PD[30-32].

\section{Electrode}
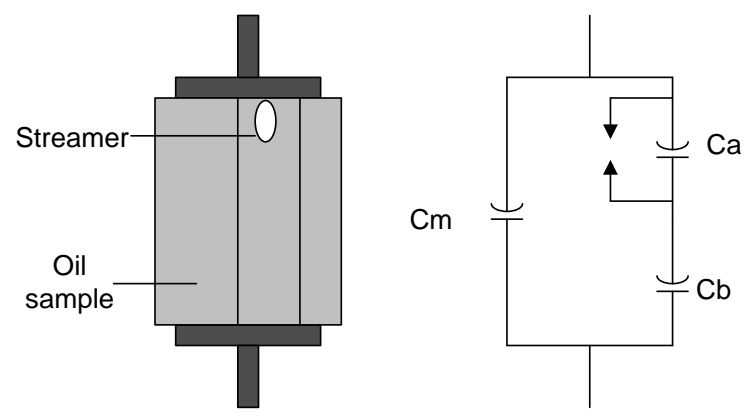

Electrode

Figure 14. Equivalent circuit of streamer in silicone oil

Insulating oil is represented as capacitances. The PD site is represented by capacitance $C_{g}$ in parallel with a spark gap. $C_{b}$ represented capacitance of the sound part of the insulation while the rest of the sample is represented by dan $C_{m}$.

If the applied voltage is $V(t)$ the voltage applied to the streamer before any discharge take place is

$$
V_{g}(t)=\frac{C_{b}}{C_{g}+C_{b}} x V(t)
$$

Therefore the magnitude for the fist discharge can be expressed as

$$
\mathrm{Q}=\mathrm{Cg}(\mathrm{kV}(\mathrm{t})-\mathrm{Vr}))
$$


Since from the experimental results it was found that $q$ reflected the value of $V(t)$ this indicated that the residual voltage after the discharge $\mathrm{Vr}$ is much smaller than $\mathrm{kV}(\mathrm{t})$. The small residual voltage resulting in a small phase shift of PD occurence. Therefore, the PD pulses concentrated around the peak of the applied voltage.

The determinant factor of early electron appearance is determined by random number that represent stochastic occasion regarding the appearance of early electron. The random number will be multiplied with the difference between applied voltage and inception voltage resulting determinant factor of early electron appearance value.

$$
P=\left(V_{e x t}-V_{i}\right) \cdot \text { Rand }
$$
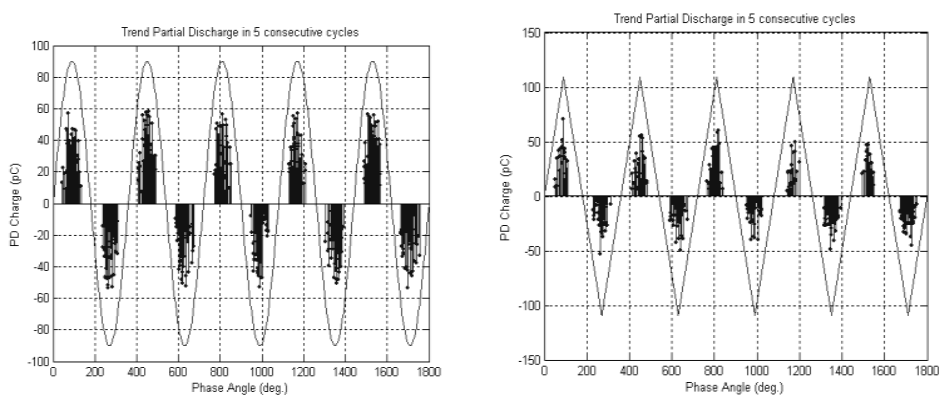

(a)
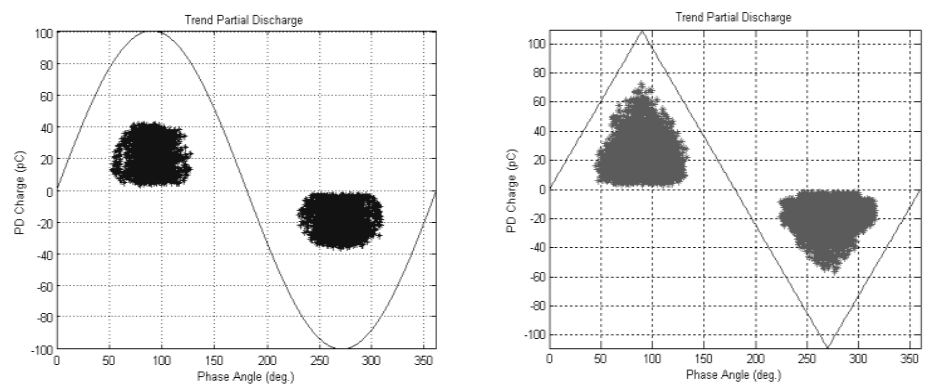

(b)
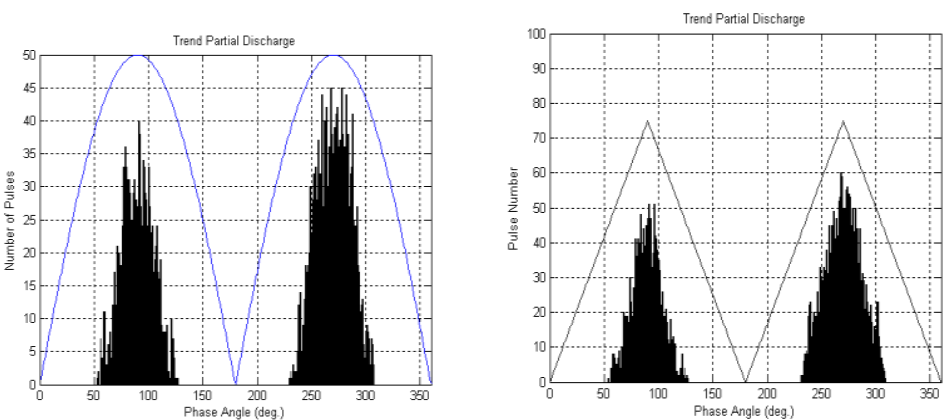

(c)

Figure 15. Simulated Pulse sequences (a) $\phi$-q-n pattern (b) and $\phi$-n pattern (c) for streamer discharges in liquid insulation under sinusoidal and triangular voltages

Where $V_{i}$ is inception voltage and Rand is random number. The number of $\mathrm{P}$ will be compared with positive/negative threshold of early electron appearance.

Positive/negative threshold of early electron appearance $\left(T_{h}\right)$ is a threshold that determines whether there is early electron or not. Positive threshold is used in positive half cycle, and 
negative threshold is used in negative one. For half positive cycle, if determinant factor is higher than positive threshold, early electron is exhibit and conduct PD phenomena. In half negative cycles, the determinant factor should below negative threshold in order to exhibit early electron that conducts PD.

Positive/negative threshold of early electron appearance depends on inception voltage and applied voltage. The higher inception voltage result the higher positive threshold and the smaller negative threshold of early electron appearance. So that early electron voltage that trigger PD will getting hard to appear in an increasing inception voltage. Nevertheless, increasing applied voltage will also decrease positive threshold and increase negative threshold of early electron appearance. So that, the discharge will be easier to occur in higher applied voltage rather than lower one. By using the model as shown in figure 14, computer simulation of PD was done and the typical results under sinusoidal, triangular and rectangular voltages are shown in figure 15. The simulated PD patterns are similar to those obtained from the experiment. These indicate the validity of the proposed streamer discharge model.

\section{Conclusions}

Partial discharge in high voltage insulation has been investigated. By utilizing computerbased measurement system time-based PD can be measured, recorded and analyzed. The PD data can be presented in various time-based patterns and can be used as finger prints of various PD sources. The experimental results indicated that in general inception voltage of positive PD is different with those of and negative PD dependent on the electrode system and material. The experimental results also clearly showed that PD in a multi sources showed a superposition characteristic. PD pattern from multi source events can be considered as the superposition of individual PD pattern from each PD source. It is obvious that time derivative of the applied voltage greatly affects the PD occurrence. It is probably that the time derivative of the applied voltage relate with the electron generation to initiate each PD event. Based on the experimental results $\mathrm{PD}$ equivalent circuit was proposed and for $\mathrm{PD}$ in liquid insulation was very similar to those have been proposed by Whitehead. Based on the proposed equivalent circuit, PD simulation was conducted and the phase-resolved PD patterns can be successfully generated under various waveforms of applied voltages.

\section{References}

[1]. Stone, E.A., Boulter, I. Culbert, H. Dhirani, Electrical Insulation for Rotating Machines, IEEE Press, 2004.

[2]. D.A. Genutis, NETAWORLD, 2006

[3]. Wester; E. Gulski; J. Smit; E. Groot, PD knowledge rules support for CBM of distribution power cables, Conference Record 2002 IEEE Int Conf on Electrical Insulation, 2002, pp. $66-69$,

[4]. T. K. Saha; P. Purkait, Investigation of an expert system for the condition assessment of transformer insulation based on dielectric response measurements, IEEE Transactions on Power Delivery, Vol. 19, No. 3, 2004, pp1127 - 1134

[5]. X. Zhang; E. Gockenbach, Asset-Management of Transformers Based on Condition Monitoring and Standard Diagnosis, IEEE Electrical Insulation Magazine, Vol. 24, No. 4, 2008, pp. 26-40

[6]. T. Bertheau; M. Hoof; T. Laird, Permanent on-line partial discharge monitoring as strategic concept tocondition based diagnosis and maintenance, Proc. Electrical Insulation Conference and Electrical Manufacturing \& Coil Winding 1999, pp. 201-2013

[7]. M. Muhr; R. Schwarz, Partial discharge measurement as a Diagnostic Tool for HVEquipments, 2006 Int. Conf. Properties and applications of Dielectric Materials, Bali, June 2006, pp. $195-198$.

[8]. J. J. Smit; O. M. Piepers; E. Gulski, Diagnostic decision support system with condition indexing for asset managers of electrical infrastructures, 2007 IEEE Int. Conf. on Systems, Man and Cybernetics, 2007, pp. 603-508 
[9]. Bozzo, R., C. Gemme, F. Guastavino, M. Cacciari, A. Contin and G.C. Montanari, 1998. Aging diagnosis of insulation systems by PD measurements. Extraction of partial discharge features in electrical treeing. IEEE Trans. Dielectrics Electric Insulations, 5: 118-124.

[10]. Chen, X., A. Cavalini and G.C. Montanari, 2008. Improving high voltage transformer reliability through recognition on PD in paper/oil system. Int. Conf. High Voltage Eng. Appl., 16: 544-548.

[11]. Suwarno, Caesario P., Anita P., Partial discharge diagnosis of Gas insulated substation (GIS) using Acoustic method, International Conference on Electrical Engineering And Informatics, Kualalumpur, 2009, DOI: 10.1109/ICEEI.2009.5254733

[12]. Whitehead S., Dielectric Breakdown of solids, Oxford Univ. Press, Clarendon. 1953.

[13]. H. Suzuki, Complex behavior of a simple-discharge model, Europhys Lett, 66, 2004, pp. 28-34.

[14]. Y. Tustsumi, T. Yonekura, T. Kikuchi, Cluster pulse criteria for recognition of partial discharge, Electrical Eng. In Japan, Vol. 113, Isue 7, Interscience, 2007, pp. 23-37.

[15]. Suwarno, Y. Suzuoki, T. Mizutani, Partial discharges due to electrical treeing in polymers, J. Phys. D: Appl. Phys., Vol. 29, 1996, pp. 2922-2931.

[16]. Suwarno, Holistic investigation of corona discharge: impulse current waveform and phase-resolved measurement, analysis and simulation Gaodianya Jishu/High Voltage Engineering, Vol. 37, Issue 11, 2011, pp. 2655-2663

[17]. Mason, J.H., Breakdown of Solid Dielectric in Divergent Fields, IEE Monograph 127 M, 102C, 1955, pp. 254-263

[18]. T. Huecker, J. Gorablenkow, UHF PD monitoring and Expert System Diagnosis, IEEE Trans. On Power Delivery, Vol. 13, No. 4, 1998, pp. 1162-1167

[19]. Y. Sekii, Degradation of LDPE and XLPE by PD, IEEE Trans. DEI, Vol. 17 No. 1, 2010, pp. 116-124

[20]. M. Florkowski, B. Florkowska, P. Zydron, PD Forms for DC Insulating Systems at higher air pressure, IET Science, Measurement and Tech., Vol. 10, Isue 1, pp. 150-157

[21]. G.C. Stone, C. Chan, H.G Sedding, relative ability of UHFenna and VHF Capacitor method to detect PD in turbine generator stator windings, IEEE Trans. DEI, Vol. 22, No. 6, 2015

[22]. Hikita, M.; Yamada, K.; Nakamura, A.; Mizutani, T.; Oohasi, A.; Ieda, M., Measurements of partial discharges by computer and analysis of partial discharge distribution by the Monte Carlo method, IEEE Transactions on Electrical Insulation, Volume 25, Issue 3, 1990 pp. $453-468$

[23]. Suwarno, Time sequential and phase-resolved measurement and analysis of corona discharge in air and streamer discharge in insulating liquid, Journal of high voltage engineering, Vol. 34 , No. 12 , 2008, pp.2583-2588.

[24]. Suwarno, Comparison between void and electrical treeing discharges in polyethylene, Proc. IEEE Int. Conf. prop. Appl. Diel. Mats., Xi,an, 2000, pp. 493-496.

[25]. Fabiani D, Montanari G C, Cavallini A, et al. Relation between space charge accumulation and partial discharge activity in enameled wires under pwm-like voltage waveforms. IEEE T Dielect El In, 2004, 11(3): 393-405

[26]. P. Wang, A. Cavallini, G.C. Montanari, The Effects of square wave rise time on PD statistics, 2015 EIC, Seatle, June, 2015

[27]. E. Corr, W.H. Siew, Analysis of PD in dielectric samples under DC exitation, Power Eng. Conference 2015, pp. 1-6

[28]. P. Trnka, J. Hornak, J. Pihara, PD under DC voltage in paper-oil insulating system, 2015 IEEE ICPADM, Sydney June 2015, pp.436-439

[29]. R. Piccin, A.R, Mor, P. Morshuis, J.Smit, PD analysis of gas insulated systems at HVAC and DC, IEEE Trans. DEI, Vol. 22, No. 1, 2015, pp. 218-228 
[30]. Suwarno ,A Model and Computer Simulation of Partial Discharges in High Voltage Liquid Insulation, Proc. Asia International Conference on Modelling \& Simulation, Kota Kinabalu, 2010, pp. 444-449

[31]. MM. Hiroshi, D. Maashi, K. Shunji, Equivalent Circuit Model of Partial Discharge in Gas Insulated Switchgears, Transactions of the Institute of Electrical Engineers of Japan. B, Vol.120-B;Np.6; 2000, pp. 905-906

[32]. M.D. Noskov, M. Sack, A.S. Malinovski, A.J. Schwab, Measurement and simulation of electrical tree growth and partial discharge activity in epoxy resin, J. Phys. D: Appl. Phys, Vol. 34, pp. 1389-1398, 2001

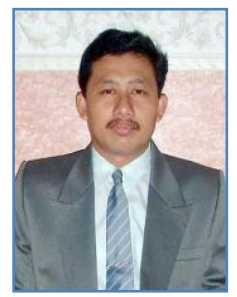

Suwarno received BSc and MSc from The Department of Electrical Engineering, Bandung Institute of Technology, Bandung, Indonesia in 1988 and 1991 respectively and PhD from Nagoya University, Japan in 1996. His research interests are High Voltage Insulating Materials and Technology, Electromagnetic Compatibility and High Voltage Industrial Application. Dr. Suwarno is recipient of The Best Paper Award from IEEE Queensland (ICPADM 1994), Excellent Paper Awards from IEE Japan 1994 and 1995 and Best Paper Presentation from ACED (Seoul 2003). Dr. Suwarno is a member of International Advisory Committee of several International Conferences. He was The General Chairman of National Conference on High Voltage Engineering 1998, IEEE ICPADM 2006, ICEEI 2007 and IEEE CMD, Bali 2012. Dr Suwarno was The Vice Dean and Dean of The School of Electrical Engineering and Informatics, Institut Teknologi Bandung and currently, he is a Professor and the head of Electrical Power Engineering Research Division of ITB. Dr. Suwarno can be reached at suwarno@ieee.org. 